\title{
Investigation on Miniature Wideband Patch Antenna for Portable Wireless and Cellular Applications
}

\author{
Xiulong Bao \\ Technological University Dublin, xiulong.bao@tudublin.ie \\ Max Ammann \\ Technological University Dublin, max.ammann@tudublin.ie
}

Follow this and additional works at: https://arrow.tudublin.ie/engschececon

Part of the Electrical and Computer Engineering Commons

\section{Recommended Citation}

Bao, X. \& Ammann, M. (2007) Investigation on miniature wideband patch antenna for portable wireless and cellular applications. VTC2007-Spring: IEEE 65th Vehicular Technology Conference, pp.348-351. Dublin, 22-25 April, 2007, doi:10.1109/VETECS.2007.83

This Conference Paper is brought to you for free and open access by the School of Electrical and Electronic Engineering at ARROW@TU Dublin. It has been accepted for inclusion in Conference papers by an authorized administrator of ARROW@TU Dublin. For more information, please contact arrow.admin@tudublin.ie, aisling.coyne@tudublin.ie,gerard.connolly@tudublin.ie. Funder: Science Foundation Ireland

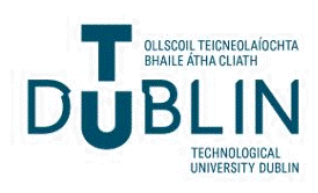




\title{
Investigation on Miniature Wideband Patch Antenna for Portable Wireless and Cellular Applications
}

\author{
X. L. Bao and M. J. Ammann \\ Centre for Telecommunications Value-chain Research, \\ School of Electronic \& Communications Engineering, \\ Dublin Institute of Technology, Kevin Street, Dublin 8, Ireland \\ Email:, xbao@electronics.dit.ie, mammann@electronics.dit.ie
}

\begin{abstract}
A low-profile miniature antenna with very wide bandwidth is proposed for emerging multimode devices. It comprises a small circular patch antenna loaded by a metallic annular-ring and located on a laminate with a slotted ground plane. The design achieves a very compact low-profile antenna with broadband performance. By optimizing the parameters of the annular-ring patch antenna, very broadband characteristics can be obtained. The measured results show that the antenna achieves a $10 \mathrm{~dB}$ return loss from from $1.383 \mathrm{GHz}$ to $2.210 \mathrm{GHz},(827 \mathrm{MHz})$ ie about $47 \%$ with respect to the centre frequency $1.796 \mathrm{GHz}$. The measured results are in good agreement with the simulated results. The radiation patterns and gains are also presented. The working frequencies for the proposed antenna include the GPS frequency $(1.575 \mathrm{GHz})$, DCS band $(1.710 \mathrm{GHz}-1.880 \mathrm{GHz})$, DECT, GSM1800 and the UMTS (1.920GHz-2.170GHz) band.
\end{abstract}

Keywords-----Patch Antenna, Broadband Antenna, Miniature antenna, Cellular, UMTS

\section{INTRODUCTION}

Microstrip patch antennas have been popular since the initial research drive in the late seventies, when a plethora of work was reported. Their low-profile nature has made then desirable for many aeronautical and mobile applications applications. The main drawbacks of narrow bandwidth and high cost has since been mitigated [1-2]. In this paper a low-cost patch antenna with very wide bandwidth is presented. It has the added feature of small size, typically $50 \%$ smaller that the ground breaking circular patches of the eighties.

In the last decade or so, annular-ring patch antennas have been reported [3-10]. An annular-ring loaded circular patch antenna has a smaller size when compared to a circular patch antenna without annular-ring for a given frequency. An annular-ring patch antenna, which comprises an inner radius $\mathrm{R} 2$ and outer radius $\mathrm{R} 1$, is resonant at a lower frequency when R2 is smaller. However, when R2 becomes much smaller, the impedance of feed point becomes large and it is difficult to match the impedance using a $50 \mathrm{Ohm}$ coaxial probe. So a circular patch embedded in an annular-ring, can provide a good match and simultaneously significantly reduce the patch size.

A compact broadband antenna is designed and fabricated. A cross-slot in the ground plane can achieve much more reduction of patch size and the introduction of a concentric slot-ring provides the broadband characteristics.

\section{DESIGN OF ANNULAR-RING PATCH WITH A SLOTTED GROUND PLANE}

A novel compact circular patch antenna loaded by annular-ring is presented. It can realize very wideband characteristics and significant miniaturization, desirable for portable wireless devices. The proposed antenna configuration is shown in Fig.1, which is printed on the 
Table 1 The parameters of the proposed antenna

\begin{tabular}{|c|c|c|c|l|l|l|l|l|l|}
\hline Parameters & Feed Point & L1 $=$ L2 & W & D1 & D2 & D3 & SD1 & SD2 & SD3 \\
\hline $\begin{array}{c}\text { Dimensions } \\
(\mathrm{mm})\end{array}$ & $\mathbf{( - 4 . 5 , - 4 . 5 )}$ & 16.0 & 1.6 & $\mathbf{2 0}$ & 15 & 10.2 & 20 & 18 & 3 \\
\hline
\end{tabular}

low-cost FR4 substrate with a relative permittivity of 4.0, the thickness of $1.52 \mathrm{~mm}$, and loss tangent of 0.02 . A coaxial of impedance $50 \mathrm{Ohm}$ is used to feed the circular patch of the proposed antenna. Further miniaturization is possible using higher cost laminates with higher values of relative permittivity. The ground plane size is $70 \mathrm{~mm} \times 70 \mathrm{~mm}$. Because the concentric annular-ring patch and the slot-ring

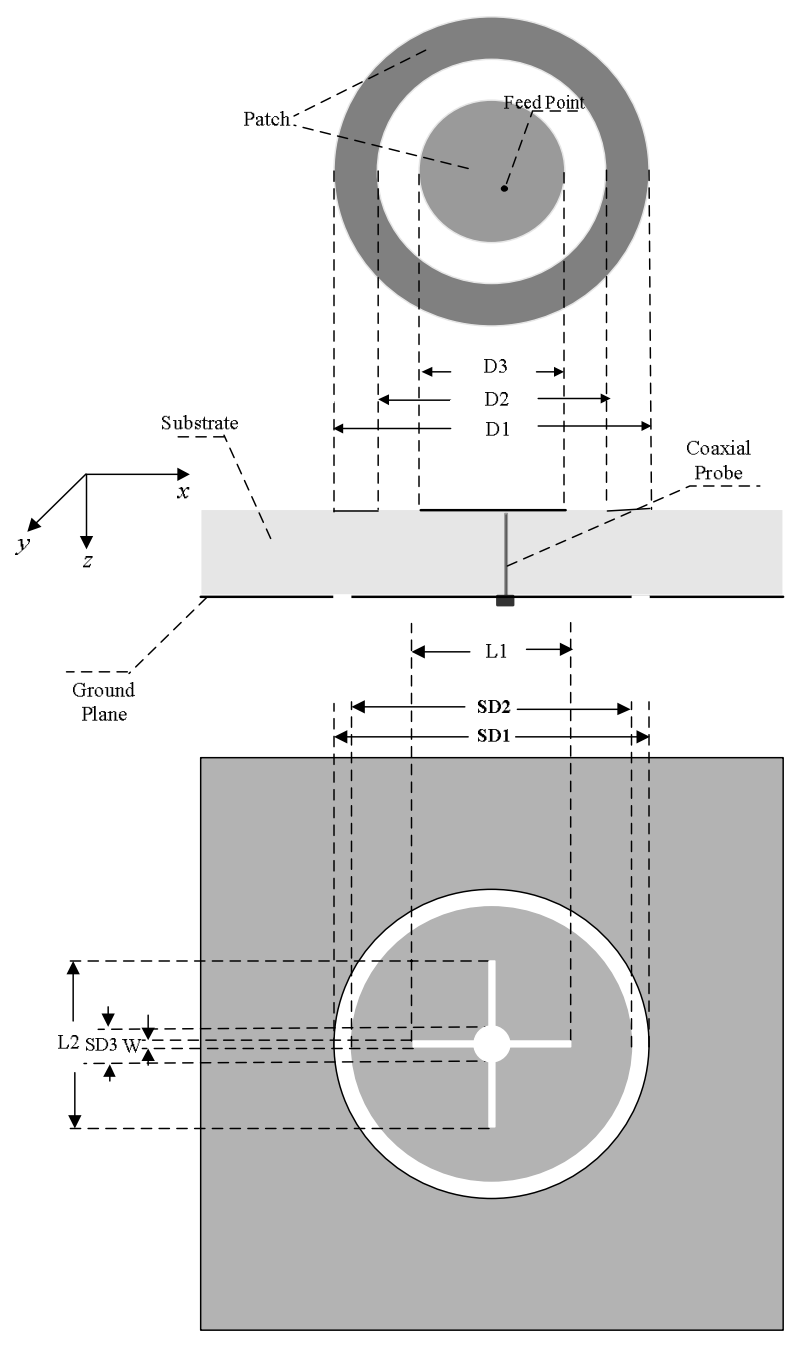

(a)

(b)

(c)

Figure 1 The geometry of the annular-ring patch antenna

(a) patch (b)substrate (c)groundplane with ring-slot and cross-slot in the ground plane can provide multiple resonant modes, a very broadband antenna can be realised by appropriately adjusting the parameters of antenna. The optimized dimensions of the proposed antenna are list in Table 1.

\section{SIMULATED AND MEASURED RESULTS}

In order to illustrate the effects of the slots in the groundplane on the antenna performance, an investigation of the proposed antenna is augmented by examining and the same annular-ring patch antenna without the annular slot and the same antenna with a normal groundplane, under the same conditions. This is done by simulation using the finite element method. The simulated results of return loss are plotted in Figure 2. It is found that the proposed antenna can effectively reduce the centre-frequency by over $100 \%$ compared to the same annular-ring patch antenna with normal groundplane and can achieve the wideband characteristics.

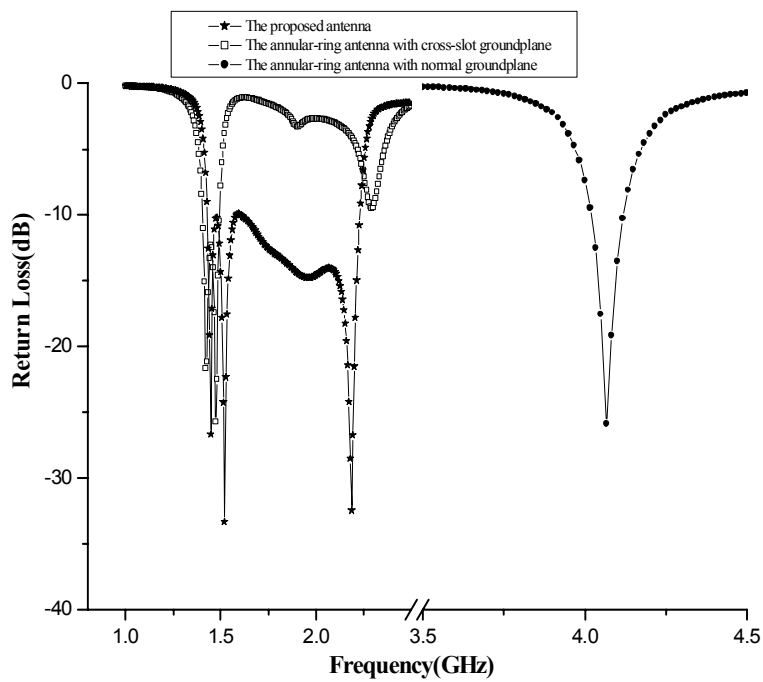

Figure 2 Comparison of three different annular-ring patch antennas 
Figure 3 shows the simulated and measured results of return losses for the proposed antenna. The simulated results are in good agreement with the measured results. The measured input impedance bandwidth for which the return loss is greater than $10 \mathrm{~dB}$ is $827 \mathrm{MHz}$, from $1.383 \mathrm{GHz}$ to $2.210 \mathrm{GHz}$, which is about $47 \%$ fractional impedance bandwidth with respect to the centre frequency of $1.796 \mathrm{GHz}$. This is a significantly large bandwidth for a microstrip patch antenna. The simulated radiation patterns at $1.575 \mathrm{GHz}, 1.800 \mathrm{GHz}$ and $1.900 \mathrm{GHz}$ are displayed for linear polarization for the $\mathrm{XoZ}$ plane and the YoZ plane in Figure 4 (a) and (b), respectively. The radiation patterns are stable and broadside at the working frequencies. The variation in gain across the bandwidth is also shown in Figure 5.
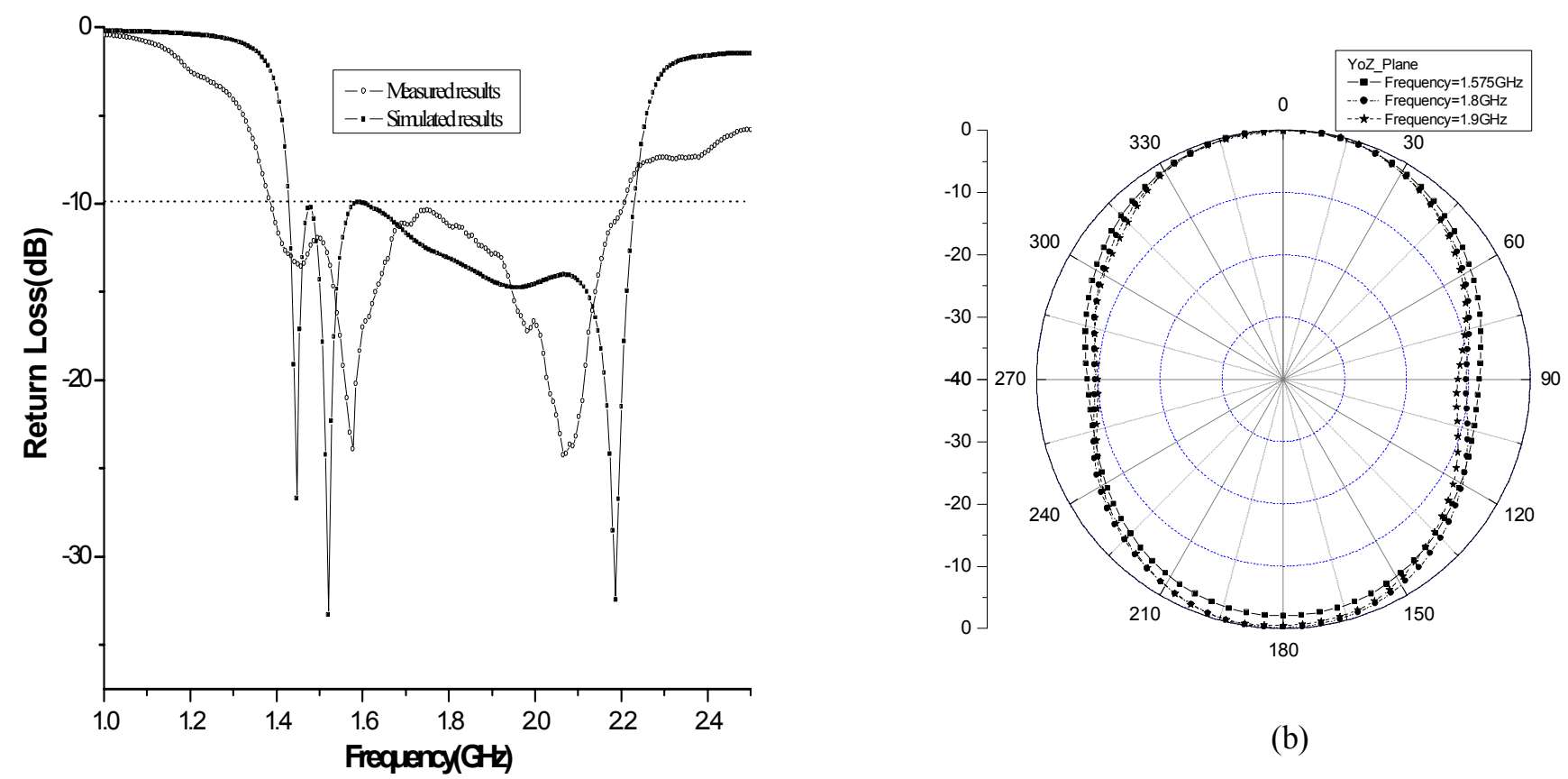

(b)

Figure 3 The comparison of the measured and simulated return loss for the proposed antenna

Figure 4 The radiation patterns for the proposed antenna at (a) XoZ plane and (b) YoZ plane 


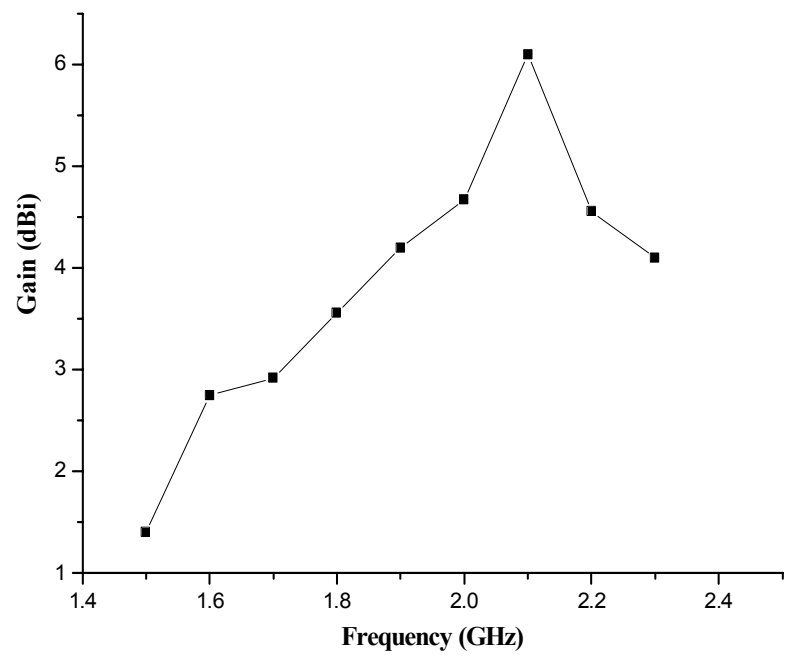

Figure 5 The variation of maximum gain for the proposed antenna

\section{CONCLUSIONS}

In this paper, a compact and broadband circular patch antenna loaded by an annular-ring patch is examined both numerically and experimentally. The results indicate the proposed antenna can realize both miniaturization and broadband characteristics simultaneously on the thin substrate. A concentric annular-ring patch antenna with a slotted ground plane may also be used to provide circular polarization and can provide multiple band characteristics, by adjusting the parameters of antenna. The antenna is proposed for the emerging multimode portable device.

\section{ACKNOWLEDGEMENT}

This work is supported by Science Foundation Ireland

\section{REFERENCES}

[1] J. R James And P. S Hall,,Handbook Of Microstrip Antenna, IEE Electromagnetic Wave series, UK 1989.

[2] D. M. Pozar, D. H. Schaubert, The Analysis and Design of Microstrip Antennas and Array Wiley IEEE Press, 1995.

[3] Z. P. Nie, W. C. Chew, Y. T. Lo, Analysis of the Annular-Ring-Loaded circular-Disk Microstrip Antenna, IEEE Transactions on Antennas and Propagation, Vol.38, No.6, June 1990, pp.806-813.

[4] Z. B. Fan, K. F. Lee, Input Impedance of Annular-Ring Microstrip, IEEE Transactions on Antennas and Propagation, Vol.40, No.8, August 1992, pp.992-995.

[5] D.M.Kokotoff, J.T.Aberle, R.B.Waterhouse, Rigorous Analysis of Probe-Fed Printed Annular Ring Antennas, IEEE Transactions on Antennas and Propagation, Vol.47, No.2, February 1999, pp.384-388

[6] N. S. Nurie, R. J. Langley, Input Impedance of Concentric Ring Microstrip Antennas for Dual Frequency Band Operation, IEE Proceedings, Vol.137, No.6, December, 1990, pp.331-336.

[7] H. T. Chen, H. D. Chen, Y. T, Cheng, Full-Wave Analysis of the Annular-Ring Loaded Spherical-Circular Microstrip Antenna, IEEE Transactions on Antennas and Propagation, Vol.45, No.11, November 1997, pp.1581-1583.

[8] H. K. Kan, R. B. Waterhouse and D. Pavlickovski, Compact Dual Concentric Ring Printed Antennas, IEE Proc.-Microw. Antennas Propag., Vol.151, No.1, February 2004, pp.37-42.

[9] J .S Row, Design of Aperture-Coupled Annular-Ring Microstrip Antennas for Circular Polarization, IEEE Transactions on Antennas and Propagation, Vol.53, No.5, May 2005, pp.1779-1784.

[10] X. L. Bao and, M. J. Ammann, Compact Annular-ring Embedded Circular Patch Antenna with Cross-slot Ground Plane for Circular Polarisation, Electronics Letters, Vo1. 42, No.4, Feb., 2006, pp. 192-193. 